\title{
Perceptions of Dental Hygienist Students toward CAD/CAM
}

\author{
Shim Youn-Soo*1, Song Eun-Ji' ${ }^{2}$, An So-Youn ${ }^{3}$, Park So-Young ${ }^{4}$ \\ 'Department Pediatric Dentistry, Dankook University Dental Hospital, 119, Dandae-ro, Dongnam-gu, Cheonan-si, \\ Chungcheongnam-do, 31116, Korea; shim-21@hanmail.net \\ 2Department Pediatric Dentistry, Wonkwang University, 77, Dunsan-ro, Seo-gu, Daejeon, 35233, Korea; \\ sej3377@naver.com \\ ${ }^{3}$ Department Dental Hygiene, Vision University College of Jeonju, 235, Cheonjam-ro, Wansan-gu, Jeonju-si, Jeolla- \\ buk-do, 55069, Korea; 9543sue@hanmail.net \\ ${ }^{4}$ Department Dental Hygiene, Sunmoon University,70, Sunmoon-ro 221 beon-gil, Tangjeong-myeon, Asan-si, \\ Chungcheongnam-do, 31460, Korea; 1101so-young@hanmail.net
}

\begin{abstract}
Objectives: The present study sought to identify the perceptions of CAD/CAM in dental hygienist students and the need to implement CAD/CAM education. Methods/Statistical Analysis: The Convenience sampling method was used to sample dental hygienist students in 3-year and 4-year colleges of four universities in the Chungcheong region. The mean (SD) was reported for each group. Student t-test and one-way ANOVA were used to assess the statistical significance of the results, with post hoc tests conducted via Tukey's HSD. $\mathrm{p}<0.05$ was considered statistically significant. All analyses were done using SPSS 22.0. Findings: A total of 254 students (40.0\%) responded that they were aware of CAD/CAM, although the vast majority of students $(528,96.4 \%)$ had no experience of using CAD/CAM. Students who have had CAD/CAM education had better perceptions of CAD/CAM $(\mathrm{p}<0.5)$. Students who have had clinical training showed more positive perceptions of dental CAD/CAM education $(\mathrm{p}<.05)$. There was a difference in the perception of dental CAD/CAM education among different grade levels $(\mathrm{p}<.05)$, with higher grades having more positive perceptions of dental CAD/CAM education ( $\mathrm{p}<.001)$. Students with better perceptions of CAD/CAM were more inclined to take CAD/CAM courses ( $p<.05)$ and had more positive perceptions of dental CAD/CAM education ( $\mathrm{p}<.05)$. Improvements/Applications: Forward dental hygienist students in the theory and practical training will take place to help you get a more professional and specific knowledge of the CAD/CAM.
\end{abstract}

Keywords: CAD/CAM, Curriculum, Dental Hygienist, Perception

\section{Introduction}

Computer-aided design/Computer-aided manufacturing (CAD/CAM) technology was introduced in dentistry in the early 1980s. This new technology, which involved designing the prostheses on a computer and using subtractive and additive processes for manufacturing, proved a useful alternative to the traditional method. Growing demands for safe and aesthetically satisfying dental materials has led to the use of new, high strength ceramics for dental prostheses, which has in turn facilitated the introduction of more sophisticated dental processing techniques and systems. Because of these concerns, digi-

*Author for correspondence 
tal dentistry using CAD/CAM is one of the major focuses of dentistry today.

The application of CAD/CAM in dentistry has opened the door to the use of new dental prosthetic materials such as zirconia $\frac{1,2}{}$. Diagnosis and treatment using high tech digital systems improves a patients' psychological response to treatment and quickly provide imaging data for the patients to view, factors that are conducive to improving a patients' understanding of their dental conditions ${ }^{3}$. For this reason, it is important for dental hygienists to keep abreast of new developments in dentistry, learning the clinical uses of digital equipment as well as theories and techniques involved with using digital equipment ${ }^{4}$. A CAD/CAM system comprises computeraided abutment scanning, restoration designing, and processing. Treatment with this integrated system considerably reduces production time and costs and resolves problems linked to the traditional production of dental restorations (e.g. issues concerning accuracy in the size of prostheses). In addition, CAD/CAM can process metals as well as zirconia. However, one considerable disadvantage is that highly expensive equipment may incur high maintenance costs. Nevertheless, the implementation of high tech digital systems is still on the rise in dentistry today.

There have been a few reports about the perceptions of CAD/CAM among dental hygienists and dental technicians in the field ${ }^{4,5} . \operatorname{In}^{\frac{5}{5}}$ conducted a study examining dental technicians' perceptions of CAD/CAM in 230 dental technical laboratories located in ${ }^{6}$ in Korea. The study's results indicated that $60.7 \%$ of dental technicians were "well aware of CAD/CAM", and most technicians have received education and actually have used $\mathrm{CAD} / \mathrm{CAM}^{5}$. A study that examined 393 dental technicians to investigate their use of digital equipment found that perceptions of the use of digital devices were more positive in technicians who have received training regarding digital equipment. Moreover, the perception and experiences of the training were significantly more favorable when their laboratories were equipped with digital equipment6. As shown here, although researchers have examined the digital literacy of dental hygienists and technicians in the actual field, the views of prospective dental hygienists, that is, students in departments of dental hygiene (3-year and 4-year col- leges), are lacking in the existing literature. This is despite the fact that about 80 schools nationwide produce more than 5,500 dental hygienists annually.

Therefore, the present study seeks to examine the current perceptions of CAD/CAM in dental hygienist students to provide preliminary data for developing an appropriate curriculum for this topic. To this end, the perceptions of CAD/CAM in dental hygienist students in four 3-year colleges and four 4-year universities in the Chungcheong region were examined. The results confirm the need for CAD/CAM courses to be implemented in the major curriculum.

\section{Materials and Methods}

\subsection{Research Subject and Method}

The present study used the non-probability convenience sampling method to develop a sample comprising dental hygienist students in two 3-year and two 4-year colleges in the Chungcheong region. The survey was conducted via a structured self-report questionnaire; the survey was anonymous for the ethical protection of the subjects. After excluding 18 questionnaires for incomplete or unreliable responses, 635 questionnaires were included in the final analysis. The study proceeded only after explaining the purpose and procedures of this study to the subjects and receiving their consents. We developed a structured questionnaire for this study and modified it based on that used in the studies by researchers $\frac{4,5}{5}$. The questionnaire comprised 6 items concerning general characteristics, 9 items concerning perceptions of utilization of digital equipment among dental hygienist students, and 6 items concerning the educational curriculum. A 5-point Likert scale was used for the perceptions of utilization of digital equipment, with higher scores indicating better perceptions. The data analyzed the reliability of the questionnaire items, and found that they were appropriate for this study (Cronbach's alpha of 0.921).

\subsection{Data Analysis}

Statistical analyses were performed using SPSS (Chicago, IL, USA) 22.0. We performed descriptive statistics for 
demographic traits, types of digital systems, and utilization, and a chi square test for comparing educational experience with general characteristics, digital uses, and intent to receive education. A Student t-test and a oneway analysis of variance were performed to examine the differences in perceptions of dental hygienist students against general characteristics, experience of digital education, and intent to receive education (Scheffe's post hoc test was performed).

\section{Results}

\subsection{General Characteristics of Subjects}

The subjects comprised more female students (618, $97.3 \%)$ than male students. Most of the subjects were in their twenties $(542,98.9 \%)$, with only a few students in the 18-19 age group $(3,0.5 \%)$ or older than $30 \mathrm{~s}$ group $(4,0.6 \%)$. A total of 382 students $(60.2 \%)$ were in
3 -year colleges, and 253 students (39.8\%) were in 4-year universities. In terms of grade-level, $208(32.8 \%)$ were second-year students, followed by $182(28.7 \%)$ first-year students, 186 (29.3\%) third-year students, and 59 (9.3\%) fourth-year students. A total of 310 students (48.8\%) answered "yes" to the item asking if the student had an experience of clinical training, while the remaining 325 $(51.2 \%)$ answered "no" as seen in Table 1.

\subsection{Perception of CAD/CAM}

In terms of perception of the importance of CAD/CAM, 254 students (40.0\%) answered "I am aware of the importance", followed by 188 students (29.6\%) answering, "I am not aware of the importance", and 193 (3.6\%) answering, "I have no opinion". The vast majority of the subjects had no experience of using CAD/CAM $(612,96.4 \%)$ and only a minority had used CAD/CAM $(23,3.6 \%)$ as seen in Table 2.

Table 1. General characteristics of study subjects $(\mathrm{N}=635)$

\begin{tabular}{|c|c|c|}
\hline \multirow{2}{*}{ Variables Category } & Frequency(\%) \\
\hline \multirow{3}{*}{ Gender } & Male & $17(2.7)$ \\
\cline { 2 - 3 } & Female & $618(97.3)$ \\
\hline \multirow{4}{*}{ Age(year) } & $18 \sim 19$ & $3(0.5)$ \\
\cline { 2 - 3 } & $20 \sim 29$ & $628(98.9)$ \\
\cline { 2 - 3 } & $30<$ & $4(0.6)$ \\
\hline \multirow{3}{*}{ School system } & College(3 years) & $382(60.2)$ \\
\cline { 2 - 3 } & College, University & $253(39.8)$ \\
\hline \multirow{3}{*}{ Grade } & Grade 1 & $182(28.7)$ \\
\cline { 2 - 3 } & Grade 2 & $208(32.8)$ \\
\cline { 2 - 3 } & Grade 3 & $186(29.3)$ \\
\cline { 2 - 3 } & Grade 4 & $59(9.3)$ \\
\hline \multirow{2}{*}{$\begin{array}{c}\text { Clinical Practice } \\
\text { Experience }\end{array}$} & Yes & $310(48.8)$ \\
\cline { 2 - 3 } & No & $325(51.2)$ \\
\hline
\end{tabular}


Table 2. Perception of CAD/CAM

\begin{tabular}{|c|c|c|}
\hline \multicolumn{2}{|c|}{ Variables Category } & Frequency(\%) \\
\hline \multirow{2}{*}{$\begin{array}{c}\text { CAD/CAM } \\
\text { Importance }\end{array}$} & Know & $254(40.0)$ \\
\cline { 2 - 3 } & Usually & $193(30.4)$ \\
\hline \multirow{2}{*}{$\begin{array}{c}\text { CAD/CAM } \\
\text { Operating Experience }\end{array}$} & Ynknown & $188(29.6)$ \\
\cline { 2 - 3 } & No & $23(3.6)$ \\
\hline
\end{tabular}

\subsection{Perception of CAD/CAM in Accordance with Clinical Training/School Curriculum}

There were significant differences in the perception of CAD/CAM depending on whether the subjects had clinical training. More specifically, when subjects had experience of clinical training, they were more likely to answer, "Dental CAD/CAM would contribute to advances in dental medicine" $(\mathrm{p}<.001)$, and had positive perceptions of education pertaining to dental CAD/ CAM ( $\mathrm{p}<.05)$. In addition, there was a significant difference in the items "receptive attitude toward CAD/CAM"

Table 3. Difference of the perception of CAD/CAM according of the experience \& School system

\begin{tabular}{|c|c|c|}
\hline & Variable Item & $\mathbf{P}$ \\
\hline \multirow{5}{*}{$\begin{array}{l}\text { CAD/CAM } \\
\text { Experience }\end{array}$} & $\begin{array}{l}\text { It has a receiving attitude with respect to the Dental } \\
\qquad \mathrm{CAD} / \mathrm{CAM}\end{array}$ & .011 \\
\hline & Think positively and for training in Dental CAD / CAM. & .002 \\
\hline & $\begin{array}{c}\text { Dental CAD / CAM are helpful in the development of dental } \\
\text { industry }\end{array}$ & .000 \\
\hline & Have interest in high-tech medical equipment. & .437 \\
\hline & $\begin{array}{l}\text { If given the opportunity I want to go completed the training for the } \\
\text { Dental CAD / CAM. }\end{array}$ & .029 \\
\hline
\end{tabular}




\section{Table 3 Continued}

\begin{tabular}{|c|c|c|}
\hline \multirow{5}{*}{$\begin{array}{l}\text { CAD/CAM } \\
\text { School system }\end{array}$} & $\begin{array}{l}\text { It has a receiving attitude with respect to the Dental } \\
\qquad \mathrm{CAD} / \mathrm{CAM}\end{array}$ & .054 \\
\hline & Think positively and for training in Dental CAD / CAM. & .077 \\
\hline & $\begin{array}{c}\text { Dental CAD / CAM are helpful in the development of dental } \\
\text { industry. }\end{array}$ & .425 \\
\hline & Have interest in high-tech medical equipment. & .070 \\
\hline & $\begin{array}{l}\text { If given the opportunity I want to go completed the training for the } \\
\text { Dental CAD / CAM. }\end{array}$ & .007 \\
\hline
\end{tabular}

and "I want to take CAD/CAM courses if I have the opportunity" depending on whether the subjects had an experience of clinical training. In terms of the effects of school curriculum on the perception of CAD/CAM, there was a significant difference in the item "I want to take CAD/CAM courses if I have the opportunity" $(\mathrm{p}<.05)$ but not in other items as seen in Table 3.

\subsection{Grade-Specific Perception of CAD/ CAM}

We examined the difference of perceptions of CAD/ CAM depending on the subjects' grade level. The findings showed that there were significant differences in the item "I have positive opinions about CAD/CAM education"

Table 4. Difference of the perception of CAD/CAM according of grade

\begin{tabular}{|c|c|c|c|c|}
\hline Item Description & \multicolumn{2}{|c|}{$\operatorname{Grade}(\mathrm{I}) \operatorname{Grade}(J)$} & ${ }^{*} \mathrm{M} \cdot \mathrm{D}(\mathrm{I}-\mathrm{J})$ & $\mathbf{P}$ \\
\hline \multirow{4}{*}{$\begin{array}{l}\text { Think positively and for training in } \\
\text { Dental CAD / CAM. }\end{array}$} & 1 & $\begin{array}{l}2 \\
3 \\
4\end{array}$ & $\begin{array}{l}.020 \\
-.179 \\
-.403\end{array}$ & $\begin{array}{l}.994 \\
.092 \\
.001\end{array}$ \\
\hline & 2 & $\begin{array}{l}1 \\
3 \\
4\end{array}$ & $\begin{array}{l}-.020 \\
-.199 \\
-.423\end{array}$ & $\begin{array}{l}.994 \\
.052 \\
.001\end{array}$ \\
\hline & 3 & $\begin{array}{l}1 \\
2 \\
4\end{array}$ & $\begin{array}{l}.179 \\
.199 \\
-.224\end{array}$ & $\begin{array}{l}.994 \\
.052 \\
.001\end{array}$ \\
\hline & 4 & $\begin{array}{l}1 \\
2 \\
3\end{array}$ & $\begin{array}{l}.403 \\
.423 \\
.224\end{array}$ & $\begin{array}{l}.994 \\
.052 \\
.001\end{array}$ \\
\hline
\end{tabular}




\section{Table 4 Continued}

\begin{tabular}{|c|c|c|c|c|}
\hline \multirow{4}{*}{$\begin{array}{l}\text { If given the opportunity I want to go } \\
\text { completed the training for the Dental } \\
\text { CAD / CAM. }\end{array}$} & 1 & $\begin{array}{l}2 \\
3 \\
4\end{array}$ & $\begin{array}{l}.040 \\
-.094 \\
-.456\end{array}$ & $\begin{array}{l}.964 \\
.684 \\
.001\end{array}$ \\
\hline & 2 & $\begin{array}{l}1 \\
3 \\
4\end{array}$ & $\begin{array}{l}.040 \\
-.094 \\
-.456\end{array}$ & $\begin{array}{l}.964 \\
.405 \\
.000\end{array}$ \\
\hline & 3 & $\begin{array}{l}1 \\
2 \\
4\end{array}$ & $\begin{array}{c}.094 \\
.134 \\
-.362\end{array}$ & $\begin{array}{l}.684 \\
.405 \\
.016\end{array}$ \\
\hline & 4 & $\begin{array}{l}1 \\
2 \\
3\end{array}$ & $\begin{array}{l}.456 \\
.495 \\
.362\end{array}$ & $\begin{array}{l}.001 \\
.000 \\
.016\end{array}$ \\
\hline
\end{tabular}

between first-years and fourth-years $(\mathrm{p}<0.05)$, secondyears and fourth years $(\mathrm{p}<0.05)$, and third-years and fourth-years $(p<0.05)$. Furthermore, there were significant differences in the answers of first-years, second-years, and third-years compared to fourth years, in the item "I will take CAD/CAM courses if I have the opportunity" $(\mathrm{p}<0.05)$, indicating a grade-specific difference in perceptions of CAD/CAM as seen in Table 4.

\subsection{Perception of CAD/CAM in Accordance with Whether Subjects Received CAD/ CAM Education}

When we examined the perceptions of CAD/CAM depending on whether the subjects received CAD/CAM education, we found that subjects who have had an experience of $\mathrm{CAD} / \mathrm{CAM}$ education show a more receptive attitude toward CAD/CAM $(\mathrm{p}<0.05)$ and perceive that

Table 5. Difference of the perception CAD/CAM according of education status

\begin{tabular}{|c|c|c|}
\hline Item Description & Mean & P \\
\hline $\begin{array}{c}\text { It has a receiving attitude with respect to the Dental } \\
\text { CAD / CAM. }\end{array}$ & .325 & .016 \\
\hline Think positively and for training in Dental CAD / CAM. & .205 & .120 \\
\hline Dental CAD / CAM are helpful in the development of dental industry. & .308 & .029 \\
\hline Have interest in high-tech medical equipment. & .101 & .486 \\
\hline $\begin{array}{c}\text { If given the opportunity I want to go completed the training for the } \\
\text { Dental CAD / CAM. }\end{array}$ & .197 & .178 \\
\hline
\end{tabular}


CAD/CAM will contribute to advances in dental field $(\mathrm{p}<.05)$. However, there were no significant differences in accordance with experience of education in other items as seen in Table 5 .

\section{Discussion}

Today, the application of computer-aided design/computer-aided manufacturing (CAD/CAM) technology in digital dentistry significantly affected the dental laboratory and clinical practices. The objective of this study was to examine the perceptions of CAD/CAM in dental hygienist students in order to assess the need for major courses and to provide preliminary data for developing $\mathrm{CAD} / \mathrm{CAM}$ curriculum in the future. Dental CAD/CAM technology has advanced remarkably in the past thirty years, rendering computer-aided production of dental restorations a norm in dentistry. CAD/CAM is utilized beyond dental clinics, constituting a critical technology in dental technical laboratories and production centers; applications include the production of various dental restorations, including inlays, onlays, crowns, fixed partial dentures, metal structures of removable partial dentures, complete dentures, dental implants, implant abutments, and maxillofacial prostheses $\frac{7-10}{}$. With the rapid advances in the medical field, the medical knowledge of patients and their demands for quality of service have also grown. Although patient satisfaction can be improved in various ways, one way would be to implement high-tech equipment to provide more accurate, but quicker, treatment for patients, to alleviate any inconveniences. Dentistry has mobilized CAD/CAM equipment in order to produce accurate and aesthetically outstanding dental prostheses more quickly and digital systems are increasingly being implemented to provide quality dental service to patients. The CAD/CAM system is particularly useful as it shortens the production time for anterior aesthetic restorations as well as for posterior prostheses using zirconia. Because of these benefits, a growing number of dental clinics are using CAD/CAM systems, despite the extravagant costs. $\mathrm{CAD} / \mathrm{CAM}$ is a groundbreaking technology in dentistry. CAD/CAM has enabled the use of intra-oral digital scanners, which reduce patients' discomfort, pain, and treatment duration. CAD/CAM also minimizes errors that arise from the chain of production processes and standardizes clinical and constructive techniques. Digital impressions resulted in a more time-efficient technique than conventional impressions. Patients preferred the digital impression technique rather than conventional techniques ${ }^{11}$.

Despite the growing availability of CAD/CAM in dental clinics, only a minority of dental hygienists utilize CAD/CAM in clinics ${ }^{4}$. Dental hygienists are professionals performing a critical role in dental treatment, and thus, it is essential that the profession adapts to the rapidly advancing high tech digital systems utilized in clinics. In a recent study, dental and dental hygiene students showed their strongest preference for e-resources that included $3 \mathrm{D}$ graphics ${ }^{12}$. The requirement for improved education of dental hygienists in this field is clear, but such programs are rarely implemented in reality. One important reason is a discrepancy between the skills demanded in clinics and the current dental hygiene curriculum. For this reason, many dental hygienist students do not even know what CAD/CAM is, let alone use it. When these students graduate and begin working at clinics, they are challenged with mastering the advanced systems of CAD/ CAM, and this may hinder rapid adaptation to their work. Therefore, it is important to promote awareness of CAD/ CAM among dental hygienist students and to provide $\mathrm{CAD} / \mathrm{CAM}$ education to foster the appropriately trained, technological adept dental hygienists demanded by dentistry today.

According to this study's findings, 254 students (40.0\%) were aware of the importance of CAD/CAM while 188 students (29.6\%) were not. In addition, there were significant differences in perceptions of CAD/CAM depending on students' grade level and whether or not they had received clinical training. For example, fourth grade students had the highest perception of CAD/CAM because of their clinical experience and more in depth knowledge.

Perceptions of CAD/CAM were also significantly different in accordance with education, with students who have had CAD/CAM education having better perceptions of CAD/CAM. It is presumed that this is because of students learning about the usefulness of CAD/CAM during their education. In addition, students with better 
perceptions of CAD/CAM were more inclined to take $\mathrm{CAD} / \mathrm{CAM}$ courses and had more positive perceptions of dental CAD/CAM education. These findings call for the development of major courses pertaining to CAD/CAM in accordance with the growing perceptions of CAD/ CAM in dental hygiene students.

According to ${ }^{4}$ and $^{5}$, most dental technicians (60.8\%) were "well aware" of CAD/CAM, but only $39.1 \%$ of dental hygienist students were simply "aware" of CAD/CAM, showing a considerable difference of awareness between dental technicians and hygienists. Furthermore, while most dental technicians answered that they had experiences with CAD/CAM and its education, most dental hygienist students (96.4\%) answered that they have not been exposed to CAD/CAM or CAD/CAM education. In a study examining dental hygienists' perceptions of the use of digital equipment, dental hygienists who had received education pertaining to digital equipment had significantly better perceptions; ; in agreement with these findings, the present study also found that dental hygienist students who have had CAD/CAM education have better perceptions of CAD/CAM. Therefore, the theoretical and clinical portions of the current dental hygiene curriculum, which fosters prospective dental hygiene clinicians, should be restructured to keep abreast with advances in the field; in particular, schools and clinics should collaborate to establish an educational environment that trains dental hygienist students, using high tech medical equipment such as CAD/CAM.

This study has a limitation in that it only examined dental hygienist students of four schools in the Chungcheong region, limiting the generalization of our results to all dental hygiene students. Furthermore, we did not compare our results with those of other various cases, and so, we were not able to obtain accurate results. Nevertheless, this study has shed some light on the perceptions of CAD/CAM systems among dental hygiene students, and we hope that this information will provide a fundamental basis for devising a curriculum that includes $\mathrm{CAD} / \mathrm{CAM}$ in the future. As argued by ${ }^{5}$, perceptions of CAD/CAM are significantly altered by the use of and by the knowledge of CAD/CAM; thus, schools should implement theoretical and clinical training to impart professional and specialized knowledge to dental hygien- ist students, who will become dental clinicians in the near future. In addition, follow-up studies should investigate means to advance CAD/CAM so as to utilize this system in more diverse fields.

\section{Conclusion}

The present study sought to identify the perceptions of CAD/CAM in dental hygienist students and the need to implement CAD/CAM education. The non-probability convenience sampling method was used to sample dental hygienist students in 3-year and 4-year colleges of four universities in the Chungcheong region. The conclusions are as follows:

- A total of 254 students (40.0\%) responded that they were aware of CAD/CAM, although the vast majority of students $(528,96.4 \%)$ had no experience of using CAD/CAM.

- Students who have had CAD/CAM education had better perceptions of CAD/CAM ( $\mathrm{p}<0.5)$.

- Students who have had clinical training showed more positive perceptions of dental CAD/CAM education $(\mathrm{p}<.05)$.

- There was a difference in the perception of dental CAD/CAM education among different grade levels $(\mathrm{p}<.05)$, with higher grades having more positive perceptions of dental CAD/CAM education $(\mathrm{p}<.001)$.

- Students with better perceptions of CAD/CAM were more inclined to take CAD/CAM courses $(\mathrm{p}<.05)$ and had more positive perceptions of dental CAD/CAM education $(\mathrm{p}<.05)$.

\section{References}

1. Bagheri H, Hooshmand T, Aghajani F. Effect of Ceramic Surface Treatments After Machine Grinding on the Biaxial Flexural Strength of Different CAD/CAM Dental Ceramics. Journal of Dentistry of Tehran University of Medical Sciences. 2015 Sep; 12(9):621-9.

2. El Named, El Ha, Halim CH. Inviter Fracture Resistance and Marginal Accuracy of Zirconia Inlay-retained Fixed 
Partial Denture: A Systematic Review. Indian Journal of Science and Technology. 2016 Feb; 9(8):1-7.

3. Miyazaki T, Hotta Y, Kunii J, Kuriyama S, Tamaki Y. A review of dental CAD/CAM: current status and future perspectives from 20 years of experience. Dental Materials Journal. 2009 Jan; 28(1):44-56.

4. Kim YS, Park HS, Koo YY. Perceptions of dental hygienists toward digital dentistry. Journal of Korean Society of Dental Hygiene. 2013 Dec; 13(6):909-16.

5. Lee JD, Park GC. The Korean Academy of Dental Technology: A Study on the Dental Technician's Perception of the Digitalization of Dental technology (Centered on the Dental Laboratories in Daegu-Gyeongbuk). 2011 Sep; 33(3):247-56.

6. Jung MA, Lee JY. Subjectivity Study about Utility Awareness of Medical Machinery of Dental Hygiene University. Students, The Korean Contents Society. 2014 May; 14(5):272-80.

7. Arnetzl G. Paving the Way for Modern All-ceramic Application in the Dental Practice. International Journal of Computerized Dentistry. 2007 Jan; 10(1):105-08.
8. Ahlholm P, Sipila K, Vallittu P, Jakonen M, Kotiranta U. Digital vs. Conventional Impressions in Fixed Prosthodontics: A Review. Journal of Prosthodontics. 2016 Aug; 2:1-7.

9. Huettig F, Prutscher A, Goldammer C, Kreutzer CA, Weber H. First clinical experiences with CAD/CAM-fabricated PMMA-based fixed dental prostheses as long-term temporaries, Clinical oral investigations. 2016 January; 20(1):161-68.

10. Alshhrani WM, Al Amri MD. Customized CAD-CAM healing abutment for delayed loaded implants. The Journal of prosthetic dentistry. 2016 Aug; 116(2):176-79.

11. Yuzbasioglu E, Kurt H, Turunc R, Bilir H. Comparison of digital and conventional impression techniques: evaluation of patients' perception, treatment comfort, effectiveness and clinical outcomes, Biomedical Central oral health. 2014 Jan; 30(14):1-7.

12. Maggio MP, Hariton-Gross K, Gluch J. The use of independent, interactive media for education in dental morphology. Journal of Dental Education. 2012 Nov; 76(11):1497-511. 